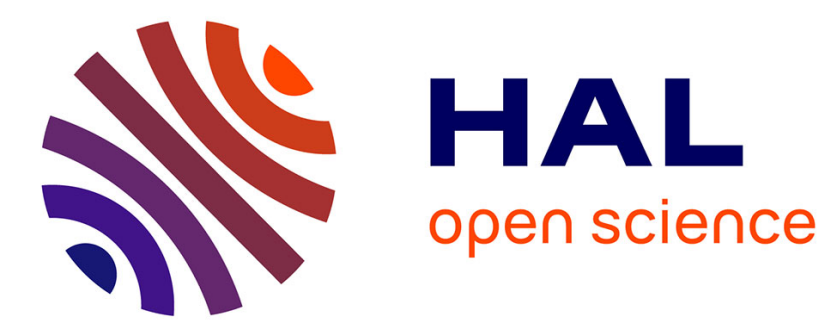

\title{
Post-synthesis annealing of coprecipitated CoFe2O4 nanoparticles in silica matrix
}

Charlotte Vichery, Mélanie Poggi, Pierre Bonville, Thierry Gacoin, Isabelle

Maurin

\section{- To cite this version:}

Charlotte Vichery, Mélanie Poggi, Pierre Bonville, Thierry Gacoin, Isabelle Maurin. Post-synthesis annealing of coprecipitated $\mathrm{CoFe} 2 \mathrm{O} 4$ nanoparticles in silica matrix. Journal of Magnetism and Magnetic Materials, 2018, 465, pp.186 - 192. 10.1016/j.jmmm.2018.05.102 . hal-01875445

\section{HAL Id: hal-01875445 \\ https://hal.science/hal-01875445}

Submitted on 8 Dec 2020

HAL is a multi-disciplinary open access archive for the deposit and dissemination of scientific research documents, whether they are published or not. The documents may come from teaching and research institutions in France or abroad, or from public or private research centers.
L'archive ouverte pluridisciplinaire HAL, est destinée au dépôt et à la diffusion de documents scientifiques de niveau recherche, publiés ou non, émanant des établissements d'enseignement et de recherche français ou étrangers, des laboratoires publics ou privés. 


\title{
Post-synthesis annealing of coprecipitated $\mathrm{CoFe}_{2} \mathrm{O}_{4}$ nanoparticles in silica matrix
}

\author{
Charlotte Vichery, ${ }^{a, b}$ Mélanie Poggi, ${ }^{a}$ Pierre Bonville, ${ }^{c}$ Thierry Gacoin, ${ }^{a}$ Isabelle Maurin,,${ }^{a *}$ \\ ${ }^{a}$ Physique de la Matière Condensée, Ecole Polytechnique, CNRS, Université Paris-Saclay, 91128 \\ Palaiseau, France \\ ${ }^{b}$ Université Clermont Auvergne, CNRS, SIGMA Clermont, ICCF, 63000 Clermont Ferrand, France \\ ${ }^{c}$ SPEC, CEA, CNRS, Université Paris-Saclay, CEA-Saclay, 91191 Gif sur Yvette, France
}

Cobalt ferrite nanoparticles $\left(d \sim 11 \mathrm{~nm}, \sigma_{\mathrm{d}}=0.5\right)$ produced by coprecipitation at room temperature are heat treated up to $1000^{\circ} \mathrm{C}$ after a preliminary dispersion in a sol-gel silica matrix to avoid aggregation and coarsening. This protected annealing allows for a significant increase of the crystallinity of the particles, as demonstrated by combined $\mathrm{x}$-ray diffraction and transmission electron microscopy experiments. A large increase in the coercive field value is reported, from 1.0 to 1.6 Tesla after annealing at $600^{\circ} \mathrm{C}$. This enhanced coercivity can be explained by the cumulative effect of an increased magnetic anisotropy and of a decreased saturation magnetization $\left(M_{\mathrm{s}}\right)$. Mössbauer spectroscopy experiments show that these evolutions of the $M_{\mathrm{s}}$ and anisotropy constant $(K)$ values originate from a small increase in canting angles and in inversion degree, i.e. a displacement of $\mathrm{Co}^{2+}$ ions from tetrahedral to octahedral sites of the spinel lattice. This study emphasizes the little impact of an improved crystallinity on saturation magnetization and canting angle values in coprecipitated $\mathrm{CoFe}_{2} \mathrm{O}_{4}$ nanoparticles and highlights that the main source of magnetic disorder is associated with the distribution of Co and Fe within the cationic sites.

Keywords: magnetic nanoparticles; cobalt ferrite; annealing; magnetic anisotropy; canting; silica host matrix 


\section{Introduction}

Spinel oxides are widely investigated in materials science because of their broad range of applications as magnetic materials, semiconductors, pigments, catalysts for water oxidation or in artificial photosynthesis cells. ${ }^{1,2}$ Their design as nanoparticles has also opened perspectives in the field of medicine and biotechnologies. ${ }^{3-5}$ Particles made of the ferrimagnetic binary oxides $\mathrm{Fe}_{3} \mathrm{O}_{4}$ and $\gamma-\mathrm{Fe}_{2} \mathrm{O}_{3}$ have been extensively studied for the development of novel or combined imaging/therapy approaches. One of the main issues related to size reduction is that the magnetic properties of the particles significantly deviate from those of their bulk counterparts. ${ }^{6}$ Many studies have emphasized the role of a surface shell made of weakly coupled and misaligned spins, which leads to a substantial decrease of saturation magnetization. ${ }^{7}$ Canted or misaligned spins may also be found in the core of the particles because of the presence of structural defects, either point defects (impurities or vacancies) ${ }^{8,9}$ or extended defects (twins, antiphase or grain boundaries) that may be related to a poor crystallinity due to the low temperatures of elaboration or to the nucleation and growth processes. ${ }^{10,11}$

For the specific case of ternary $\mathrm{MFe}_{2} \mathrm{O}_{4}$ nanoparticles (with $\mathrm{M}$ a divalent metal ion), the inversion degree, which characterizes the cationic distribution over the interstitial sites of the $\mathrm{AB}_{2} \mathrm{O}_{4}$ spinel structure, is also of importance. $\mathrm{A}$ and $\mathrm{B}$ here stand for tetrahedral and octahedral cation sites in a cubic close packing of oxygen atoms. The inversion degree $(x)$ is defined as the fraction of tetrahedral A sites occupied by trivalent ions: $\left(\mathrm{M}_{1-x} \mathrm{Fe}_{x}\right)_{\mathrm{A}}\left[\mathrm{M}_{x} \mathrm{Fe}_{2-x}\right]_{\mathrm{B}} \mathrm{O}_{4}$. If $\mathrm{Fe}^{3+}$ ions occupy only octahedral sites, the ferrite is called normal $(x=0)$, whereas if $\mathrm{Fe}^{3+}$ ions occupy equally tetrahedral and octahedral sites, the ferrite is named inverse $(x=1)$. In nanoparticles, the inversion degree can significantly deviate from that of the bulk materials. ${ }^{12}$ It may also vary depending on the synthesis protocol ${ }^{13-15}$ and the 
thermal history of the sample. ${ }^{16-18}$ In the case of cobalt ferrite $\left(\mathrm{CoFe}_{2} \mathrm{O}_{4}\right)$ studied for high frequency or stress sensing applications, ${ }^{19-21}$ the inversion degree will both affect magnetization values, as the A and B sublattices are antiferromagnetically coupled, and the anisotropy energy. ${ }^{22}$ In addition, the strength of the magnetic exchange interaction is also expected to vary ${ }^{16}$ and, as a consequence, the canting angles of the magnetic moments for ions located in A and B sites. ${ }^{23}$

The primary goal of this study is to assess the influence of annealing treatments on the magnetic properties of $11 \mathrm{~nm} \mathrm{CoFe} \mathrm{O}_{4}$ nanoparticles prepared by coprecipitation at room temperature. Such an investigation is of importance to establish a clear comparison with synthesis routes involving high temperatures such as autocombustion of metal salts or decomposition of organometallic precursors. In that latter case, formation of nanoparticles by thermolysis of the Co and Fe precursors in high-boiling point solvents typically occurs at about $200-300^{\circ} \mathrm{C}$. As the saturation magnetization $\left(M_{\mathrm{s}}\right)$ and magnetic anisotropy constant $(K)$ show a marked dependence on particle size, ${ }^{24}$ we used a so-called protected annealing $\operatorname{process}^{25,26}$ to avoid any coarsening of the particles during heating and investigate the impact of heat treatments on $M_{\mathrm{s}}, K$ and canting angle values at fixed particle size.

\section{Materials and methods}

An aqueous dispersion of cobalt ferrite nanoparticles was prepared by coprecipitation of $\mathrm{Co}^{2+}$ and $\mathrm{Fe}^{3+}$ salts in alkaline medium. $\mathrm{Fe}\left(\mathrm{NO}_{3}\right)_{3} \cdot 9 \mathrm{H}_{2} \mathrm{O}$ and $\mathrm{Co}\left(\mathrm{NO}_{3}\right)_{2} \cdot 6 \mathrm{H}_{2} \mathrm{O}$ powders were first dissolved in $70 \mathrm{~mL}$ of $\mathrm{HCl}$ at $0.33 \mathrm{~mol} . \mathrm{L}^{-1}$, with a 2 to $1(\mathrm{Fe} / \mathrm{Co})$ atomic ratio and a cobalt salt concentration of $0.14 \mathrm{~mol} . \mathrm{L}^{-1}$. Potassium hydroxide $\left(32 \mathrm{~mL}, 10 \mathrm{~mol} . \mathrm{L}^{-1}\right)$ was quickly poured into this acidic solution under vigorous stirring. The slurry was agitated during $30 \mathrm{~min}$ and then heated up to reflux for $2 \mathrm{~h}$. The resulting cobalt ferrite particles were washed with distilled water and finally dispersed by peptization in $30 \mathrm{~mL}$ of nitric acid at $\mathrm{pH}$ 
2. The solution was sonicated during $2 \mathrm{~min}$, centrifuged at $11,400 \mathrm{~g}$ for $20 \mathrm{~min}$, and the supernatant recovered in order to lower the size polydispersity. $\mathrm{CoFe}_{2} \mathrm{O}_{4}$ particles were then embedded in a sol-gel $\mathrm{SiO}_{2}$ matrix. $11 \mathrm{~mL}$ of a solution of tetraethoxysilane (TEOS) in ethanol $\left(2.25\right.$ mol. $\left.\mathrm{L}^{-1}\right)$ were first hydrolyzed by adding $2.25 \mathrm{~mL}$ of $\mathrm{HCl}$ solution at $\mathrm{pH}$ 1.15. The resulting mixture was heated for $1 \mathrm{~h}$ at $60^{\circ} \mathrm{C} .0 .5 \mathrm{~mL}$ (respectively $3.8 \mathrm{~mL}$ ) of the $\mathrm{CoFe}_{2} \mathrm{O}_{4}$ colloid were added to the sol leading, after a drying step at $100^{\circ} \mathrm{C}$, to a composite materials with a $\mathrm{Co} / \mathrm{Si}$ atomic ratio of 0.004 (respectively 0.03 ). These atomic ratios were derived from Inductively Coupled Plasma Atomic Emission Spectroscopy. The $\mathrm{CoFe}_{2} \mathrm{O}_{4} / \mathrm{SiO}_{2}$ powders were subsequently heated in air at different temperatures (400$1000^{\circ} \mathrm{C}$ ) for 3 hours. All heating and cooling stages were carried out with a sweep rate of $4^{\circ} \mathrm{C} \cdot \mathrm{min}^{-1}$.

Powder X-ray diffraction patterns were recorded using a PANalytical X'Pert diffractometer equipped with a $\mathrm{Cu} \mathrm{K} \alpha$ anode $(\lambda=1.5418 \AA)$ and a rear-side graphite monochromator. Peak positions were extracted using the Fit subroutine of the Fullprof suite of programs. ${ }^{27}$ The lattice constant was determined by least-square refinement of the interspacing distances, after correction for instrumental shifts using a silicon internal calibrant. The structural coherence length was evaluated through Pseudo-Voigt peak profile analysis, ${ }^{28}$ after correction for the instrumental resolution function. The crystallinity, morphology and size distribution of the particles were also investigated by transmission electron microscopy (TEM) using a Philips CM30 microscope operating at $300 \mathrm{kV}$. Magnetization measurements were performed with a SQUID magnetometer (Cryogenic Ltd SX600, $H_{\max }=5 \mathrm{~T}$ ) for magnetization measurements between 5 and $300 \mathrm{~K}$, a SQUID magnetometer (Quantum Design MPMS-5) equipped with an oven for measurements between 300 and $800 \mathrm{~K}$ and a Vibrating Sample Magnetometer equipped with a $14 \mathrm{~T}$ magnet (Cryogenic Ltd) for 
measurements at high magnetic fields. Samples were mounted in polycarbonate capsules with the powder immobilized by paraffin wax. For high-temperature measurements, the powder samples were wrapped into a piece of aluminum foil. Magnetic data were systematically corrected for the diamagnetic contributions of the silica matrix, wax and polycarbonate capsule or Al foil. Due to dehydration of the silica matrix and of the ferrite particles during annealing, the fraction of magnetic material in each sample was derived from the iron content measured by ICP-AES. Note that the $\mathrm{Fe} / \mathrm{Co}$ atomic ratio is close to 2 for the three samples (2.02(4) for the crude particles; 2.01(5) and 1.95(5) for the low and high particle loading in the composite samples, respectively). A Mössbauer spectrometer, operating in constant acceleration mode with a ${ }^{57} \mathrm{Co}: \mathrm{Rh} \gamma$-ray source and a $7 \mathrm{~T}$ magnetic field, was used to record absorption spectra in transmission geometry.

\section{Results and discussion}

A representative image of the size distribution of the $\mathrm{CoFe}_{2} \mathrm{O}_{4}$ colloid determined by TEM is displayed in Figure 1a. The particles are rather polydispersed in size, with a diameter in the range $3-22 \mathrm{~nm}$. Fit of the size histogram to a log-normal function yields a mean diameter value $\left(d_{\mathrm{m}}\right)$ of $11.5 \mathrm{~nm}$ and a standard deviation $\left(\sigma_{d}\right)$ of 0.5 (Figure 1b). As reported in a previous work related to the annealing of maghemite particles in silica matrix, ${ }^{26}$ no flocculation nor aggregation were observed after addition of the magnetic colloid into the silica sol, leading to homogeneous $\mathrm{CoFe}_{2} \mathrm{O}_{4} / \mathrm{SiO}_{2}$ composite powders after gelation and drying (see Figure 1c). 


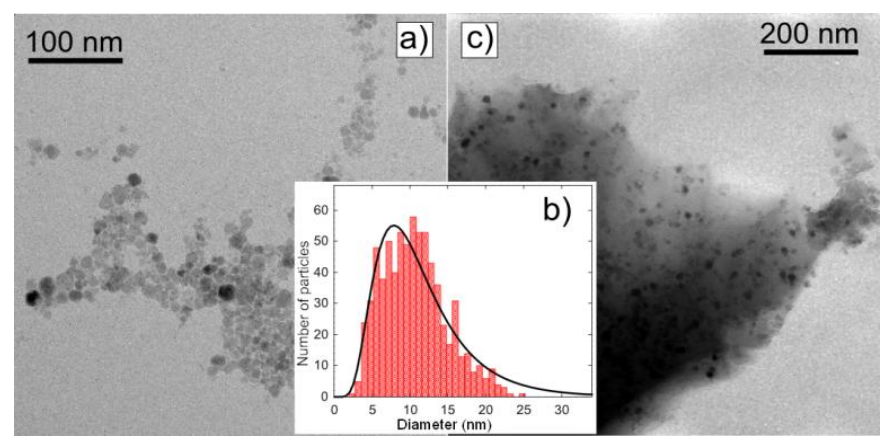

Fig. 1. (a) TEM micrograph of the crude $\mathrm{CoFe}_{2} \mathrm{O}_{4}$ particles; (b) histogram of the particle size distribution (statistics over ca. 800 particles) where the solid line is a fit to a log-normal function; (c) TEM micrograph of the concentrate $\mathrm{CoFe}_{2} \mathrm{O}_{4} / \mathrm{SiO}_{2}$ composite sample, $\mathrm{Co} / \mathrm{Si}=0.03$.

To monitor the evolution of the size and of the crystal structure upon thermal treatment, $\mathrm{x}-$ ray diffraction (XRD) measurements were performed on the $\mathrm{CoFe}_{2} \mathrm{O}_{4} / \mathrm{SiO}_{2}$ composite with $\mathrm{Co} / \mathrm{Si}=0.03$. The corresponding profiles are shown in Figure 2, after the drying stage $\left(100^{\circ} \mathrm{C}\right)$ and after annealing at $400,600,800$ and $1000^{\circ} \mathrm{C}$. All patterns can be indexed using the $\mathrm{Fd} \overline{3} \mathrm{~m}$ space group of $\mathrm{CoFe}_{2} \mathrm{O}_{4}$. After heat treatment at $1000^{\circ} \mathrm{C}$, two additional peaks are detected indicating the formation of a secondary phase (see arrows in Figure 2). These Bragg reflections correspond to the two most intense peaks of fayalite $\left(\alpha-\mathrm{Fe}_{2} \mathrm{SiO}_{4}, \mathrm{JCPDS}\right.$ 01-070-1861). The presence of this impurity phase is already observed after annealing at $800^{\circ} \mathrm{C}$, but its amount is much reduced. This parasitic reaction was not reported in the case of $\gamma-\mathrm{Fe}_{2} \mathrm{O}_{3}$ nanoparticles produced by a similar coprecipitation route and dispersed in silica. ${ }^{26}$ Therefore, the $\alpha-\left(\mathrm{Fe}_{1-\mathrm{x}} \mathrm{Co}_{\mathrm{x}}\right)_{2} \mathrm{SiO}_{4}$ impurity phase could result from a higher surface reactivity of the $\mathrm{CoFe}_{2} \mathrm{O}_{4}$ particles. An alternative explanation would be the presence of free ions due to partial dissolution and release of $\mathrm{Co}^{2+}$ and $\mathrm{Fe}^{2+}$ in acidic conditions, ${ }^{29,30}$ such as those used for TEOS hydrolysis. 


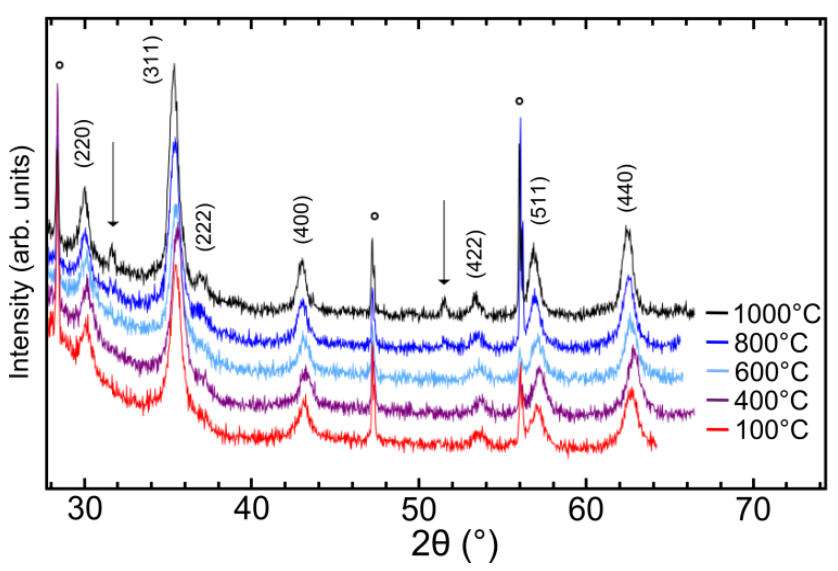

Fig. 2. $\mathrm{X}$-ray diffraction profiles $(\lambda=1.5418 \AA)$ of $\mathrm{CoFe}_{2} \mathrm{O}_{4}$ nanoparticles embedded in silica $(\mathrm{Co} / \mathrm{Si}=0.03)$ dried at $100^{\circ} \mathrm{C}$ and annealed at selected temperatures. The peaks related to the $\mathrm{Si}$ calibrant are indicated by open circles and the ones corresponding to fayalite by arrows. Indexation refers to the $F d \overline{3} m$ space group of cobalt ferrite.

The lattice parameter $(a)$ and coherence length $\left(L_{c}\right)$ values are summarized in Table 1 for crude particles and for particles dispersed in silica. The coherence length of the assynthesized particles is about $9 \mathrm{~nm}$, i.e. close to the mean particle size derived from the TEM observations. This value is relatively constant upon thermal treatment for particles embedded in silica, whereas $L_{c}$ is doubled between 100 and $800^{\circ} \mathrm{C}$ for the crude particles. This result confirms the homogeneous distribution of particles within the $\mathrm{SiO}_{2}$ binder and the efficiency of this matrix to prevent grain growth through sintering of the initial particles. Similar results were reported for $\gamma-\mathrm{Fe}_{2} \mathrm{O}_{3}$ nanoparticles. ${ }^{26,31}$ However, $L_{c}$ only increases from 8 to $16 \mathrm{~nm}$ after heating at $800^{\circ} \mathrm{C}$ for crude $\mathrm{CoFe}_{2} \mathrm{O}_{4}$ particles $\left(53 \mathrm{~nm}\right.$ at $\left.1000^{\circ} \mathrm{C}\right)$, while we observed a much larger grain growth above $450^{\circ} \mathrm{C}$ for the iron oxide (with $L_{c}$ values of more than $100 \mathrm{~nm}$ after treatment at $800^{\circ} \mathrm{C}$ ), associated with a transformation in hematite. ${ }^{26}$ 


\section{Table 1}

Lattice parameter $(a)$ and coherence length $\left(L_{c}\right)$ values for $\mathrm{CoFe}_{2} \mathrm{O}_{4}$ particles embedded in silica $(\mathrm{CS}, \mathrm{Co} / \mathrm{Si}=$ $0.03)$ and for crude particles (C), after annealing at selected temperatures.

\begin{tabular}{ccccc}
\hline$T_{\text {annealing }}\left({ }^{\circ} \mathrm{C}\right)$ & \multicolumn{2}{c}{$a(\AA)( \pm 0.005)^{i}$} & \multicolumn{2}{c}{$L_{c}(\mathrm{~nm})( \pm 0.5)^{i}$} \\
\cline { 2 - 5 } & $\mathrm{CS}$ & $\mathrm{C}$ & $\mathrm{CS}$ & $\mathrm{C}$ \\
\hline 100 & 8.375 & 8.370 & 9.3 & 8.2 \\
400 & 8.356 & 8.355 & 9.1 & 8.0 \\
600 & 8.373 & 8.371 & 9.7 & 10.1 \\
800 & 8.392 & 8.378 & 10.5 & 16.0 \\
1000 & 8.396 & 8.387 & 13.2 & 53.0 \\
\hline
\end{tabular}

${ }^{i}$ the error bar on the $a$-parameter is mostly representative of instrumental line shifts, whereas the standard deviation on $L_{c}$ derives from the fitting.

For the samples dried at $100^{\circ} \mathrm{C}$, the $a$-parameter values are significantly smaller than the ones expected from the Poix's model: $a=8.410 \AA$ for normal $(x=0)$ and $a=8.385 \AA$ for inverse $(x=1) \mathrm{CoFe}_{2} \mathrm{O}_{4}$ spinel oxide. ${ }^{32}$ Such a reduced $a$-parameter is commonly reported for cobalt ferrite nanoparticles, ${ }^{23,29,33}$ and should be assigned to the low temperature of elaboration rather than to an impact of size or surface energy terms. Indeed, the lattice constant of both crude and embedded particles shows a similar evolution upon heating (see Table 1), while there is grain growth for the former (surface/volume ratio divided by 2 from the increase in the $L_{c}$ value) and almost no size change for the latter. The $a$-value of $8.37 \AA$ may result from the presence of strain in the crystal structure but the nature of the crystalline defects is probably important to determine the sense of variation of the $a$-parameter, as strain generated by ball milling was found to increase the lattice constant in the work of Liu and Ding. ${ }^{34}$ Here, only heat treatments above $800^{\circ} \mathrm{C}$ allow recovering the lattice constant of bulk $\mathrm{CoFe}_{2} \mathrm{O}_{4}(a=8.392 \AA$, JCPDS 022-1086 card), similarly to what was reported by Soler et al.. ${ }^{29}$ To some extent, this lattice expansion may be related to an improved crystallinity. Indeed, the increase of the coherence length observed for both crude and embedded particles definitely proves that atomic diffusion in the volume and at the surface is effective above 
$800^{\circ} \mathrm{C}$. This higher crystallinity is also confirmed by the high-resolution TEM images shown in Figures $3 \mathrm{a}$ and $3 \mathrm{~b}$, as the particles annealed at $800^{\circ} \mathrm{C}$ appear clearly more facetted than the pristine ones. Note however that post-annealing is not equivalent to direct synthesis in high boiling point solvent as $\mathrm{CoFe}_{2} \mathrm{O}_{4}$ nanoparticles produced at $\sim 150{ }^{\circ} \mathrm{C}$ by forced hydrolysis in polyol were found exhibit high crystallinity and bulk $a$-values right after synthesis. $^{35}$

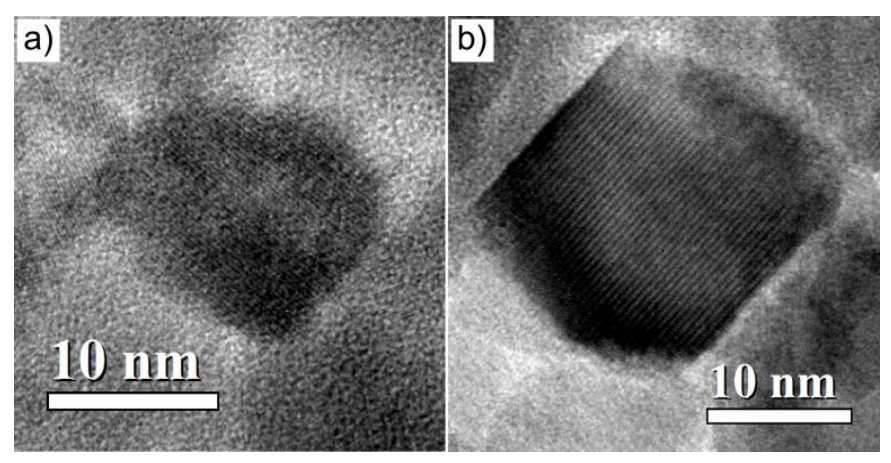

Fig. 3. High-resolution TEM images of the $\mathrm{CoFe}_{2} \mathrm{O}_{4}$ particles before (a) and after annealing at $800^{\circ} \mathrm{C}$ (b), which show the facetted character of the particles after heat treatment.

To get quantitative information on the inversion degree, Mössbauer absorption spectra were recorded at $4.2 \mathrm{~K}$ with a $7 \mathrm{~T}$ magnetic field applied parallel to the $\gamma$-ray propagation direction. Measurements were performed on crude particles heat treated at 100 and $800^{\circ} \mathrm{C}$ (Figure 4). Note that the use of crude particles permits not only to obtain better resolved spectra but also to avoid the contribution of the fayalite impurity phase. The as-obtained spectra were fitted using two sextets, corresponding to the contribution of iron in tetrahedral (A) and in octahedral (B) sites. The relative weight of the two subspectra $\left(\mathrm{P}_{\mathrm{A}} / \mathrm{P}_{\mathrm{B}}\right)$ allows for the calculation of the inversion degree $x$, which refers to the fraction of $\mathrm{Co}^{2+}$ ions in octahedral environment. The isomer shift value, with respect to $\alpha-F e$, is equal to $0.26 \mathrm{~mm} / \mathrm{s}$ for iron in A sites and $0.38 \mathrm{~mm} / \mathrm{s}$ for iron in B sites, in agreement with a trivalent state. 
Values of the $\mathrm{P}_{\mathrm{A}} / \mathrm{P}_{\mathrm{B}}$ ratio, inversion degree $(x)$ and hyperfine fields $\left(H_{\mathrm{hf}}\right)$ for $\mathrm{Fe}$ in $\mathrm{A}$ and $\mathrm{B}$ sites are listed in Table 2.

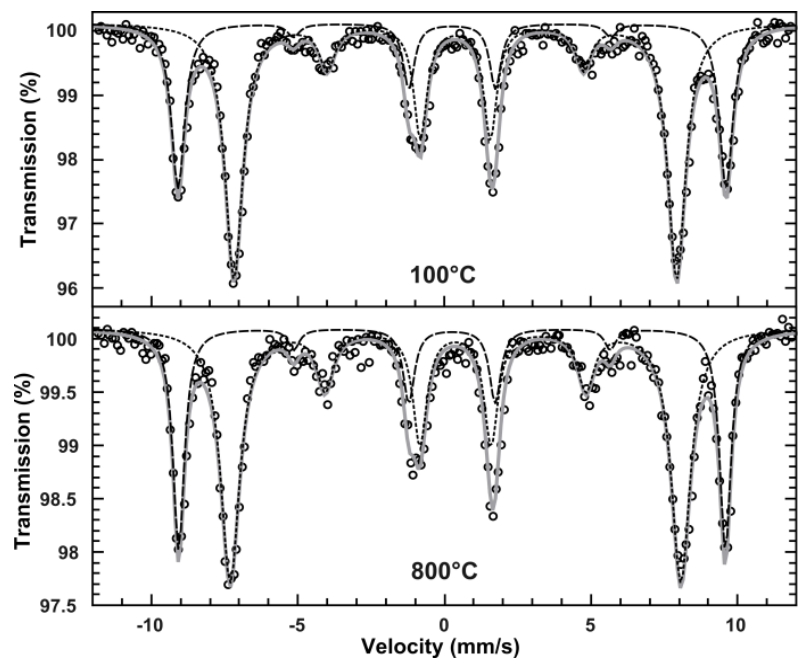

Fig. 4. ${ }^{57} \mathrm{Fe}$ Mössbauer absorption spectra recorded at $4.2 \mathrm{~K}$ under a $7 \mathrm{~T}$ magnetic field for crude $\mathrm{CoFe}_{2} \mathrm{O}_{4}$ particles heat treated at 100 and $800^{\circ} \mathrm{C}$. The magnetic field is applied parallel to the $\gamma$-ray propagation direction. The dashed and dotted black lines correspond to the contribution of iron in tetrahedral and in octahedral sites, respectively. The bold grey solid lines refer to the fitted spectra.

\section{Table 2}

Mössbauer spectroscopy results for crude $\mathrm{CoFe}_{2} \mathrm{O}_{4}$ particles heat-treated at 100 and $800^{\circ} \mathrm{C}$.

\begin{tabular}{ccccccc}
\hline & $\begin{array}{c}\mathrm{P}_{\mathrm{A}} / \mathrm{P}_{\mathrm{B}} \\
( \pm 0.02)\end{array}$ & $\begin{array}{c}x \\
( \pm 0.04)\end{array}$ & $\begin{array}{c}H_{\mathrm{hf}}(\mathrm{A}) \\
(\mathrm{T})\end{array}$ & $\begin{array}{c}H_{\mathrm{hf}}(\mathrm{B}) \\
(\mathrm{T})\end{array}$ & $\begin{array}{c}\theta(\mathrm{A}) \\
\left( \pm 2^{\circ}\right)\end{array}$ & $\begin{array}{c}\theta(\mathrm{B}) \\
\left( \pm 1^{\circ}\right)\end{array}$ \\
\hline $100^{\circ} \mathrm{C}$ & 0.47 & 0.64 & 51.2 & 53.0 & 21 & 23 \\
$800^{\circ} \mathrm{C}$ & 0.49 & 0.66 & 51.2 & 53.6 & 24 & 27 \\
\hline
\end{tabular}

For the as-synthesized particles, the inversion degree is close to 0.67 , i.e. representative of a random distribution of $\mathrm{Co}$ and $\mathrm{Fe}$ in the cationic sites of the spinel structure (Table 2). This value is consistent with what was previously found for low-temperature synthesis routes, ${ }^{12,36-38}$ for which we anticipate kinetically-controlled cation incorporation. Displacement of $\mathrm{Co}^{2+}$ ions from $\mathrm{A}$ to $\mathrm{B}$ sites is expected upon heating, because of their higher stabilization in octahedral coordination. However, the inversion degree is found to 
hardly increase upon heating up to $800^{\circ} \mathrm{C}$, in fair agreement with earlier works. ${ }^{37,39}$ Additional measurements performed with the $7 \mathrm{~T}$ magnetic field applied perpendicular to the $\gamma$-ray propagation direction confirmed the absence of large changes in inversion, with $x$ values of $0.61,0.60,0.64$ and $0.66( \pm 0.04)$ for samples heat treated at $100,400,600$ and $800^{\circ} \mathrm{C}$, respectively. Note that all samples were cooled down to room temperature at $4^{\circ} \mathrm{C} / \mathrm{min}$ after heating. Hence, the smooth change of $x$ values with the annealing temperature would not account for some quenching of a high-temperature disordered state as reported in previous works, ${ }^{16-18}$ but rather reflects the absence of large cationic rearrangements due to the limited temperature range. Entropy-favored randomization would actually be expected by heating above $900-1000^{\circ} \mathrm{C} .^{17}$

In the next section, we discuss the influence of post-synthesis annealing on the magnetic properties of these coprecipitated $\mathrm{CoFe}_{2} \mathrm{O}_{4}$ nanoparticles. Samples were first characterized by hysteresis cycles measured in the blocked state, with magnetization $(M)$ expressed per gram of $\mathrm{CoFe}_{2} \mathrm{O}_{4}$. $M(H)$ loops were recorded at $10 \mathrm{~K}$ for the dilute composite samples $(\mathrm{Co} / \mathrm{Si}=0.004)$, so that the influence of interparticle interactions can be neglected as a first approximation. ${ }^{25}$ Note that samples heat treated up to $600^{\circ} \mathrm{C}$ will be mostly considered in the following to ensure that the observed evolutions are not related to the presence of fayalite, which is antiferromagnetic at $10 \mathrm{~K} .{ }^{40}$ We observed that the coercive field value $\left(\mu_{0} H_{c}\right)$ changes significantly upon annealing (Figure 5). $\mu_{0} H_{c}$ equals 1.0, 1.2 and $1.6 \mathrm{~T}$ for the particles heat treated at 100,400 and $600^{\circ} \mathrm{C}$, respectively (Table 3). A similar evolution is reported for the crude particles. A modified Stoner-Wohlfarth model predicts that the coercive field value of an assembly of non-interacting and randomly oriented single-domain particles with cubic anisotropy can be expressed as: ${ }^{24,41}$ 
$\mu_{0} H_{c}(T)=\frac{0.96 K}{M_{s}}\left(1-\left(4 \frac{25 k_{B} T}{K V}\right)^{\frac{3}{4}}\right)$

Eq. 1

where $k_{B}$ is the Boltzmann constant. As a result, for particles of fixed size, $\mu_{0} H_{c}$ is inversely proportional to the saturation magnetization $\left(M_{s}\right)$, and increases when the anisotropy constant $(K)$ increases. A modification of $M_{s}$ and/or of $K$ should thus be responsible for the large changes in $H_{c}$ reported in the present study, as the protected annealing process did not lead to a substantial increase of the particle size.

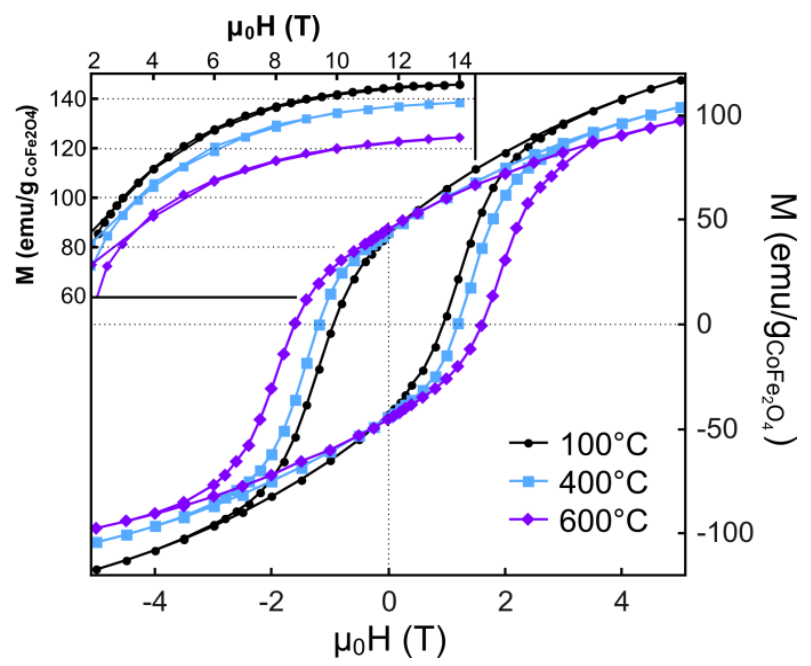

Fig. 5. Magnetization at $10 \mathrm{~K}$ as a function of magnetic field for $\mathrm{CoFe}_{2} \mathrm{O}_{4}$ nanoparticles embedded in silica $(\mathrm{Co} / \mathrm{Si}=0.004)$ and annealed at selected temperatures. In inset, the high-magnetic field part of the $M(H)$ curves obtained by VSM measurements.

Table 3

Magnetic characterization of $\mathrm{CoFe}_{2} \mathrm{O}_{4}$ nanoparticles embedded in silica and annealed at selected temperatures.

\begin{tabular}{ccccc}
\hline & $\begin{array}{c}M_{\mathrm{s}}(10 \mathrm{~K})^{a} \\
( \pm 5 \mathrm{emu} /\end{array}$ & $\begin{array}{c}M_{\mathrm{s}}(265 \mathrm{~K})^{b} \\
( \pm 2 \mathrm{emu} /\end{array}$ & $\begin{array}{c}\mu_{0} H_{c}(10 \mathrm{~K})^{c} \\
( \pm 0.05 \mathrm{~T})\end{array}$ & $\begin{array}{c}T_{\text {peak }}{ }^{d} \\
( \pm 1 \mathrm{~K})\end{array}$ \\
\hline $100^{\circ} \mathrm{C}$ & 146 & 49 & 1.00 & - \\
$400^{\circ} \mathrm{C}$ & 139 & 48 & 1.20 & 367 \\
$600^{\circ} \mathrm{C}$ & 125 & 45 & 1.60 & 390 \\
\hline
\end{tabular}

${ }^{a}$ magnetization value under $14 \mathrm{~T},{ }^{b}$ magnetization value under $11 \mathrm{~T},{ }^{c}$ coercive field at $10 \mathrm{~K},{ }^{d}$ temperature of the maximum of the ZFC curve. 
To assess the evolution of $M_{s}$ at $10 \mathrm{~K}$, additional magnetization measurements were carried out using a VSM magnetometer equipped with a $14 \mathrm{~T}$ magnet. The corresponding curves are plotted in the inset of Figure 5. The saturation field corresponds to about $14 \mathrm{~T}$, irrespective of the annealing temperature. The saturation magnetization values of the different samples, hereafter taken as the magnetization values at $14 \mathrm{~T}$, are reported in Table 3 . We observed that $M_{s}(10 \mathrm{~K})$ continuously decreases when increasing the annealing temperature. Measurements performed under $11 \mathrm{~T}$ between 5 and $275 \mathrm{~K}$ show that this decreased magnetization is actually effective over the whole temperature range (see the $M_{\mathrm{s}}(265 \mathrm{~K})$ values in Table 3 for instance). This evolution may thus explain part of the changes in coercivity.

From Eq. 1, one can derive the value of the magnetic anisotropy constant at $10 \mathrm{~K}$ using the experimental $M_{s}$ and $\mu_{0} H_{c}$ values and the mean volume of the particles. The corresponding $K$ values are $0.9,1.0$ and $1.2( \pm 0.1) \times 10^{7} \mathrm{erg} / \mathrm{cm}^{3}$ for samples heat-treated 100,400 and $600^{\circ} \mathrm{C}$, respectively. We should thus also expect an increase in magnetic anisotropy upon annealing. This finding was experimentally confirmed by Zero Field Cooled (ZFC) magnetization measurements performed on a magnetometer equipped with a furnace because of the high anisotropy of cobalt ferrite $\left(K \sim 2 \times 10^{7} \mathrm{erg} / \mathrm{cm}^{3}\right.$ at zero Kelvin for bulk $\left.\mathrm{CoFe}_{2} \mathrm{O}_{4}\right),{ }^{42}$ which leads to blocking temperatures higher than room temperature. Samples were first heated up to 575 or $675 \mathrm{~K}$ (depending on their annealing temperature), and then cooled down to room temperature under zero magnetic field. Magnetization was then measured on heating, under a magnetic field of $25 \mathrm{G}$. The composite sample dried at $100^{\circ} \mathrm{C}$ has not been measured this way, as heating above 375-400 K (i.e., in the superparamagnetic state) could have induce some modification of the magnetic properties. Figure 6 shows that the maximum of the ZFC magnetization curves indeed increases upon annealing, indicating 
an increase of the blocking temperature $\left(T_{B}\right)$ and of the magnetic anisotropy constant $(K . V=$ $100 k_{B} \cdot T_{B}$ for cubic anisotropy).

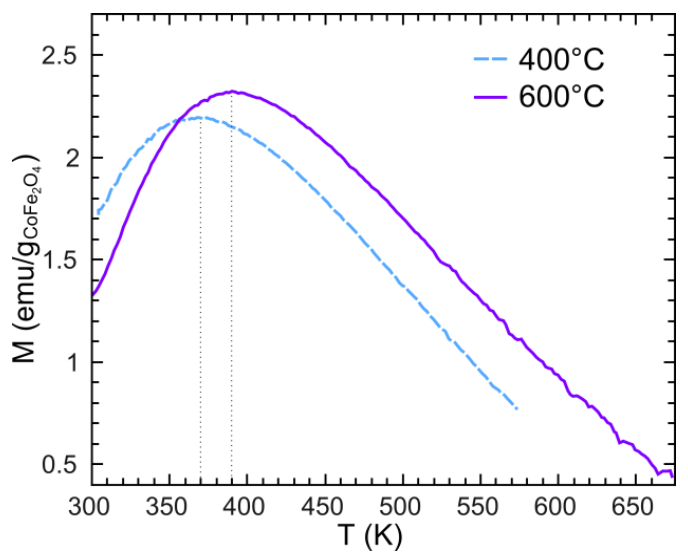

Fig. 6. Zero Field Cooled magnetization measurements under $25 \mathrm{G}$ for $\mathrm{CoFe}_{2} \mathrm{O}_{4}$ nanoparticles embedded in silica $(\mathrm{Co} / \mathrm{Si}=0.004)$ and annealed at 400 and $600^{\circ} \mathrm{C}$.

This enhanced anisotropy is probably mostly representative of an increased inversion degree (Table 2). Indeed, the anisotropy of $\mathrm{Co}^{2+}$ ions is much larger in octahedral than in tetrahedral environment, ${ }^{22}$ so that small changes in inversion can lead to substantial modifications of the effective anisotropy constant. In addition, as the particle size exceeds $10 \mathrm{~nm}$, the impact of the surface on the magnetic properties is fairly weak, ${ }^{35,43,44}$ and modification of the surface anisotropy $\left(K_{\mathrm{s}}\right)$ due to deshydroxylation, as reported for $7 \mathrm{~nm} \gamma-\mathrm{Fe}_{2} \mathrm{O}_{3}$ nanoparticles, ${ }^{26}$ should have a minor contribution to the observed changes.

An increased inversion degree is also expected to decrease the saturation magnetization value because of the smaller magnetic moment of $\mathrm{Co}^{2+}\left(3 \mu_{\mathrm{B}}\right)$ compared to $\mathrm{Fe}^{3+}\left(5 \mu_{\mathrm{B}}\right)$. However, the small changes in inversion degree, from 0.64 (before) to 0.66 (after annealing at $800^{\circ} \mathrm{C}$ ), cannot explain a decrease by $\sim 8$ to $15 \%$ of the $M_{s}$ values at $265 \mathrm{~K}$ or $10 \mathrm{~K}$, respectively (Table 3). Another important insight may be gained by considering the evolution of the canting angles upon annealing. Indeed, misaligned spins are expected in the volume of the particles, ${ }^{45}$ because the presence of both $\mathrm{Co}$ and $\mathrm{Fe}$ in the two cationic sites 
give rise to multiple exchange interaction values and spin frustration. ${ }^{16,23}$ Canting angle values can be extracted for iron from fits of the in-field Mössbauer absorption spectra because the relative intensity $I$ of the pair of $2^{\text {nd }}$ and $5^{\text {th }}$ lines depends on the canting angle $\theta$. In the parallel configuration (with the field direction parallel to that of the $\gamma$ beam), it writes: $I=4 \sin ^{2}(\theta) /\left(1+\cos ^{2}(\theta)\right) .{ }^{45}$ In the absence of canting, the $2^{\mathrm{d}}$ and $5^{\text {th }}$ lines are extinct. These canting angles are representative of a static canting between the magnetic moments in tetrahedral (A) or octahedral (B) site and the direction of the external field. As shown in Table 2, canting is present in both sites in agreement with other works, ${ }^{23,36}$ with rather large $\theta$ angles. The $\theta_{\mathrm{A}}$ and $\theta_{\mathrm{B}}$ angles slightly increase after annealing at $800^{\circ} \mathrm{C}$, also contributing to the magnetization decrease.

Note that these canting angle values of $\sim 22^{\circ}$ are comparable to those reported for $2.5 \mathrm{~nm}$ $\left(\mathrm{Co}_{0.24} \mathrm{Fe}_{0.76}\right)\left[\mathrm{Co}_{0.76} \mathrm{Fe}_{1.24}\right] \mathrm{O}_{4}$ particles, that were attributed to a surface contribution. ${ }^{35}$ Indeed, in this later work, an increase of the particle size to $6 \mathrm{~nm}$ was found to decrease the canting angles from $\sim 25$ to $\sim 17^{\circ}$. For our $11 \mathrm{~nm}$ coprecipitated particles, we expect the canting to be representative of a volume contribution mostly influenced by the spatial distribution of $\mathrm{Co}$ and $\mathrm{Fe}$ ions. The decreased inversion in our samples ( 0.67 vs. 0.76 in ref 35) is expected to give rise to a wider distribution of environments and presumably more canting that could explain the $\theta$ values reported in this work. Moreover, the linewidths corresponding to $\mathrm{Fe}^{3+}$ in tetrahedral coordination $\left(\Gamma_{\mathrm{A}}\right)$ tend to decrease with heating and the opposite trend is observed for $\mathrm{Fe}^{3+}$ in octahedral sites $\left(\Gamma_{\mathrm{B}}\right),{ }^{46}$ reflecting different evolutions in the hyperfine environment of the two ions. The decreased $\Gamma_{\mathrm{A}}$ values probably account for structural changes as $\Gamma_{\mathrm{A}}$ is not severely impacted by the nature of the neighbors as already stressed by Sawatsky et al., ${ }^{16,47}$ and thus by inversion. In contrast, the exchange interaction for $\mathrm{Fe}^{3+}$ in $\mathrm{B}$ site is strongly weakened when its next neighbor in $\mathrm{A}$ site changes from $\mathrm{Fe}^{3+}$ to 
$\mathrm{Co}^{2+}$. As a consequence, $\Gamma_{\mathrm{B}}$ is more sensitive to the local environment and its increase could result from an enhanced chemical disorder.

Modification of the magnetic properties of nanoferrites with annealing is complex, ${ }^{48}$ with opposite evolutions reported by different authors and/or strong correlations with a particle size increase. ${ }^{49,50}$ Our results using a protected annealing approach allows to draw more definite conclusions. The variation of the $a$-cubic parameter upon heating, as well as the increased coherence length and the morphological changes observed by TEM evidence an enhanced crystallinity and definitely prove atomic diffusion at or above $800^{\circ} \mathrm{C}$. However, inversion between Co and Fe must be restricted to exchanges between nearest neighbors and not over long distances. The presence of vacancies on the octahedral cationic sites would have favored a rearrangement at low temperatures, presumably $250-300^{\circ} \mathrm{C}$ according to ref. 51 , but in the case of vacancy-free $\mathrm{CoFe}_{2} \mathrm{O}_{4}$, inversion requires heating above $900^{\circ} \mathrm{C}^{36}$ Two interpretations can be proposed to account for the increased canting and the opposite evolutions of the Mössbauer linewidths upon annealing. The first one involves local strain relaxations, in part related to inversion because of the differences in ionic radius for $\mathrm{Co}^{2+}$ and $\mathrm{Fe}^{3+}$ species. These structural changes tend to homogenize the environment around $\mathrm{Fe}^{3+}$ in A site and thus decrease the width of the distribution in hyperfine fields, with hardly any change in the canting angle $\theta_{\mathrm{A}}$. On the other side, magnetic exchanges for $\mathrm{Fe}^{3+}$ in $\mathrm{B}$ site are more sensitive to the nature of the neighbors in A site. The increased Mössbauer linewidths after thermal treatment reflect an enhanced magnetic disorder and thus of frustration, which leads to an increased canting in $\mathrm{B}$ site. The evolution of $\Gamma_{\mathrm{B}}$ would then mostly account for the change in inversion.

The alternative explanation considers gradients of the $\mathrm{Co} / \mathrm{Fe}$ atomic ratio in the volume of the particles as mentioned in ref 23 for citrate autocombustion methods. For aqueous 
coprecipitation, a former study has emphasized the fact that the kinetics for $\mathrm{Co}^{2+}$ insertion in magnetite is slower than that of $\mathrm{Fe}^{2+}$ or that the leaching of $\mathrm{Co}^{2+}$ in acid is much faster, leading to cobalt incorporation twice smaller than expected and large quantities of Co adsorbed at the surface of the iron oxide. ${ }^{51}$ Another work related to the coprecipitation of $\mathrm{Fe}^{2+}, \mathrm{Fe}^{3+}$ and $\mathrm{Co}^{2+}$ from hydroxides suggested the formation of a heterogenous phase and intergrowth of microdomains with slightly distinct compositions from the study of diffraction line broadening. ${ }^{36}$ Here, the $\mathrm{Co} / \mathrm{Fe}$ ratio is maintained from the precursors to the solid phase, so that separation in rich and poor cobalt regions might occur. Such segregation would explain the $\Gamma_{\mathrm{B}}$ increase with annealing because of partial homogenization upon heating. Indeed, $\mathrm{FeCo}_{2} \mathrm{O}_{4}$ is referred to as a normal spinel ${ }^{52}$ and $\mathrm{Co}$ preferentially occupy octahedral cationic sites in maghemite, so that homogenization will induce changes in the nature of the nearest neighbors for $\mathrm{Fe}^{3+}$ ions in $\mathrm{B}$ site as it goes from pure $\mathrm{Co}$ (or $\mathrm{Fe}$ ) to mixed (Fe, Co) environment. However, both the diffraction coherence length which is not very small with respect to the particle sizes and the magnitude of the canting angles suggest that heterogeneities are less pronounced than in citrate autocombustion routes $\left(\sim 22^{\circ}\right.$ vs. $40^{\circ}$ for the $\theta$ values in ref. 23). Comparison with the works of Artus $^{35}$ and Baaziz ${ }^{53}$ shows that $^{35}$ the design of new synthetic strategies to favor high crystallinity or to circumvent differences in reactivity between the $\mathrm{Fe}$ and $\mathrm{Co}$ precursors is more efficient that post-synthesis annealing to get homogenous hyperfine environments and less canting.

\section{Conclusions}

Post-synthesis heat treatments have been performed on $\sim 11 \mathrm{~nm}$ sized cobalt ferrite nanoparticles produced by coprecipitation in water and dispersed in a sol-gel silica matrix. This protected annealing process allowed increasing their crystallinity while preventing 
them from aggregation and growth. The presence of this matrix also limits the impact of inter-particle interactions on magnetic evolutions upon heating. We reported a displacement of cobalt ions from tetrahedral to octahedral sites, with an inversion degree that slightly increases from 0.64 after synthesis to 0.66 after annealing at $800^{\circ} \mathrm{C}$. Treatments at higher temperatures were found to be limited by side reaction with the host silica matrix. A rather large increase of the coercive field value was observed, from 1.0 to 1.6 Tesla after annealing. This evolution results from the combination of a slight increase in magnetic anisotropy, due to the increased inversion, and of a decrease in saturation magnetization, because of the change in inversion and of an increased canting. This study highlights that improving the crystallinity of cobalt ferrite nanoparticles does not necessarily lead to an increase in saturation magnetization or a decreased canting in the volume of the particles: for $\mathrm{CoFe}_{2} \mathrm{O}_{4}$, these two parameters are mostly influenced by inversion, and annealing temperatures below $1000^{\circ} \mathrm{C}$ does not allow for a large redistribution of $\mathrm{Fe}$ and $\mathrm{Co}$ in the cationic sites.

\section{Acknowledgements}

The authors thank P. Berthet for valuable discussion and assistance with the hightemperature magnetic measurements. P.E. Coulon from the Laboratoire des Solides Irradiés (CNRS/Ecole Polytechnique) is also acknowledged for TEM observations. The research described here has been supported by Triangle de la Physique (contract 2008-051T).

\section{References}


[1] I.C. Nlebedimn, N. Ranvah, P.I. Williams, Y. Melikhov, J.E. Snyder, A.J. Moses, D.C. Jiles, Effect of heat treatment on the magnetic and magnetoelastic properties of cobalt ferrite, J. Magn. Magn. Mater. 322 (2010) 1929-1933.

[2] A. Indra, P.W. Menezes, N.R. Sahraie, A. Bergmann, C. Das, M. Tallarida, D. Schmeißer, P. Strasser, M. Driess, Unification of catalytic water oxidation and oxygen reduction reactions: amorphous beat crystalline cobalt iron oxides, J. Am. Chem. Soc. 136 (2014) 17530-17536.

[3] P. Tartaj, M. Del Puerto Morales, S. Veintemillas-Verdaguer, T. Gonzales Carreno, C.J. Serna, The preparation of magnetic nanoparticles for applications in biomedicine J. Phys. D: Appl. Phys. 36 (2003) R182-97.

[4] I. Sharifi, H. Shokrollahi, S. Amiri, Ferrite-based magnetic nanofluids used in hyperthermia applications, J. Magn. Magn. Mater. 324 (2012) 903-915.

[5] J. Kudr, Y. Haddad, L. Richtera, Z. Heger, M. Cernak, V. Adam, O. Zitka, Magnetic nanoparticles: from design and synthesis to real world applications, Nanomaterials 7 (2017) 243.

[6] X. Batlle, A. Labarta, Finite-size effects in fine particles: magnetic and transport properties, J. Phys. D: Appl. Phys. 35 (2002) R15-R42.

[7] A. Millan, A. Urtizberea, N.J.O. Silva, F. Palacio, V.S. Amaral, E. Snoeck, V. Serin, Surface effects in maghemite nanoparticles, J. Magn. Magn. Mater. 312 (2007) L5-L9.

[8] S. Mørup, Spin-canting and transverse relaxation at surfaces and in the interior of ferrimagnetic particles, J. Magn. Magn. Mater., 266 (2003) 110-118.

[9] M.P. Morales, C.J. Serna, F. Bodker, S. Morup, Spin canting due to structural disorder in maghemite, J. Phys.: Condens. Matter, 9 (1997) 5461-5467.

[10] B. Luigjes, S.M.C Woudenberg, R. de Groot, J.D. Meeldijk, H.M. Torres Galvis, K.P. de Jong, A.P. Philipse, B. Erné, Diverging geometric and magnetic size distributions of iron oxide nanocrystals, J. Phys. Chem. C 115 (2011) 14598-14605.

[11] M. Levy, A. Quarta, A. Espinosa, A. Figuerola, C. Wilhelm, M. Garcia-Hernandez, A. Genovese, A. Falqui, D. Alloyeau, R. Buonsanti, P. Cozzoli, M. Garcia, F. Gazeau, T. Pellegrino, Correlating magneto-structural properties to hyperthermia performance of highly monodisperse iron oxide nanoparticles prepared by a seeded-growth route, Chem. Mater. 23 (2011) 4170-4180.

[12] S. Gyergyek, D. Makovec, A. Kodre, I. Arcon, M. Jagodic, M. Drofenik, Influence of synthesis method on structural and magnetic properties of cobalt ferrite nanoparticles, J. Nanopart. Res. 12 (2010) 1263-1273. 
[13] J.B. da Silva, N.D.S. Mohallem, E. Sinnecker, M.A. Novak, A.S. Alburquerque, J.D. Ardisson, W.A. Macedo, Magnetic studies of $\mathrm{CoFe}_{2} \mathrm{O}_{4} / \mathrm{SiO}_{2}$ aerogel and xerogel nanocomposites, J. Nanosci. Nanotechnol. 9 (2009) 5932-5939.

[14] C.N. Chinnasamy, M. Senoue, B. Jeyadevan, O. Perales-Perez, K. Shinoda, K. Tohji, Synthesis of size-controlled cobalt ferrite particles with high coercivity and squareness ratio, J. Colloid Interface Sci. 263 (2003) 80-83.

[15] D. Peddis, C. Cannas, G. Piccaluga, E. Agostinelli, D. Fiorani, Spin-glass-like freezing and enhanced magnetization in ultra-small $\mathrm{CoFe}_{2} \mathrm{O}_{4}$ nanoparticles, Nanotechnology 21 (2010) 125705.

[16] G. Sawatzky, F. van der Woude, A. Morrish, Mössbauer Study of Several Ferrimagnetic Spinels, Phys. Rev. 187 (1969) 747-757.

[17] M.R.D. Guire, R.C. O'Handley, G. Kalonji, The cooling rate dependance of cation distributions in $\mathrm{CoFe}_{2} \mathrm{O}_{4}$, J. Appl. Phys. 65 (1989) 3167-3172.

[18] Y.C. Wang, J. Ding, J.H. Yin, B.H. Liu, J.B. Yi, S. Yu, Effects of heat treatment and magnetoannealing on nanocrystalline Co-ferrite powders, J. Appl. Phys. 98 (2005) 124306.

[19] Y. Suzuki, R.B. van Dover, E.M. Gyorgy, J.M. Philips, V. Korenivski, D.J. Werder, C.H. Chen, R.J. Cava, J.J. Krajewski, W.F. Peck, K.B. Do, Structure and magnetic properties of epitaxial spinel ferrite thin films, Appl. Phys. Lett. 68 (1996) 714-716.

[20] Y. C. Wang, J. Ding, J.B. Yi, B.H. Liu, T. Yu, Z. X. Shen, High-coercivity Co-ferrite thin films on (100)- $\mathrm{SiO}_{2}$ substrate, Appl. Phys. Lett. 84 (2004) 2596-2598.

[21] I.C. Nlebedim, R.L. Hadimani, R. Prozorov, D.C. Jiles, Structural, magnetic, and magnetoelastic properties of magnesium substituted cobalt ferrite, J. Appl. Phys. 113 (2013) 17A928.

[22] H.Y. Zhang, B.X. Gu, H.R. Zhai, M. Lu, Y.Z. Miao, S.Y. Zhang, Anisotropy and Faraday effect in Co spinel ferrite films, J. Appl. Phys. 75 (1994) 7099-7102.

[23] D. Peddis, N. Yaacoub, M. Ferretti, A. Martinelli, G. Piccaluga, A. Musinu, C. Cannas, G. Navarra, J.M. Grenèche, D. Fiorani, Cationic distribution and spin canting in $\mathrm{CoFe}_{2} \mathrm{O}_{4}$ nanoparticles, J. Phys.: Cond. Matter 23 (2011) 426004.

[24] B.D. Cullity, C.D. Graham, Introduction to magnetic materials, $2^{\text {nd }}$ ed., Wiley, Ed., 2009.

[25] I. Maurin, G. Dantelle, J.P. Boilot, T. Gacoin, A protected annealing process for the production of high quality colloidal oxide nanoparticles with optimized physical properties, J. Mater. Chem. C 1 (2013) 13-22. 
[26] C. Vichery, I. Maurin, P. Bonville, J.P. Boilot, T. Gacoin, Influence of protected annealing on the magnetic properties of $\gamma-\mathrm{Fe}_{2} \mathrm{O}_{3}$ nanoparticles, J. Phys. Chem. C 116 (2012) 1631116318.

[27] J. Rodriguez-Carvajal, Recent advances in magnetic structure determination by neutron powder diffraction, Physica B 192 (1993) 55-69.

[28] J. Langford, Accuracy in Powder Diffraction II, NIST Spec. Pub. 846 (1992) 110-126.

[29] M.A.G. Soler, E.C.D. Lima, S.W. da Silva, T.F.O. Melo, A.C.M. Pimenta, J.P. Sinnecker, R.B. Azevedo, V.K. Garg, A.C. Oliveira, M.A. Novak, P.C. Morais, Aging Investigation of Cobalt Ferrite Nanoparticles in Low pH Magnetic Fluid, Langmuir 23 (2007) 9611-9617.

[30] E.E. Sileo, L.G. Rodenas, C.O. Paiva-Santos, P.W. Stephens, P.J. Morando, M.A. Blesa, Correlation of reactivity with structural factors in a series of Fe(II) substituted cobalt ferrites, J. Solid State Chem. 79 (2006) 2237-2244.

[31] C. Chanéac, E. Tronc, J.P. Jolivet, Magnetic iron oxide-silica nanocomposites. Synthesis and characterization, J. Mater. Chem. 6 (1996) 1905-1911.

[32] P. Poix, Séminaire de Chimie de l'Etat Solide VI, 1 (1966-1967) 82.

[33] C. Nordhei, A.L. Ramstad, D.G. Nicholson, Nanophase cobalt, nickel and zinc ferrites: synchrotron XAS study on the crystallite size dependence of metal distribution, Phys. Chem. Chem. Phys. 10 (2008) 1053-1066.

[34] B.H. Liu, J. Ding, Strain-induced high coercivity in $\mathrm{CoFe}_{2} \mathrm{O}_{4}$ powders, Appl. Phys. Lett. 88 (2006) 042506.

[35] M. Artus, L. Ben Tahar, F. Herbst, L. Smiri, F. Villain, N. Yaacoub, J.M. Grenèche, S. Ammar, F. Fiévet, Size-dependent magnetic properties of $\mathrm{CoFe}_{2} \mathrm{O}_{4}$ nanoparticles prepared in polyol, J. Phys.: Condens. Matter 23 (2011) 506001.

[36] T.A.S. Ferreira, J.C. Waerenborgh, M.H.R.M. Mendonça, M.R. Nunes, F.M. Costa, Structural and morphological characterization of $\mathrm{FeCo}_{2} \mathrm{O}_{4}$ and $\mathrm{CoFe}_{2} \mathrm{O}_{4}$ spinels prepared by a coprecipitation method Solid State Sciences 5 (2003) 383-392.

[37] D. Carta, M.F. Casula, A. Falqui, D. Loche, G. Mountjoy, C. Sangregorio, A. Corrias, A Structural and Magnetic Investigation of the Inversion Degree in Ferrite Nanocrystals $\mathrm{MFe}_{2} \mathrm{O}_{4}$ (M = Mn, Co, Ni), J. Phys. Chem. C 113 (2009) 8606-8615. 
[38] G. Concas, G. Spano, C. Cannas, A. Musinu, D. Peddis, G. Piccaluga, Inversion degree and saturation magnetization of different nanocrystalline cobalt ferrites, J. Magn. Magn. Mater. 321 (2009) 1893-1897.

[39] D. Carta, G. Mountjoy, G. Navarra, M. F. Casula, D. Loche, S. Marras, A. Corrias, X-ray Absorption Investigation of the Formation of Cobalt Ferrite Nanoparticles in an Aerogel Silica Matrix, J. Phys. Chem. C 111 (2007) 6308-6317.

[40] F. Belley, E.C. Ferré, F. Martin-Hernandez, M. J. Jackson, M. D. Dyar, E.J. Catlos, The magnetic properties of natural and synthetic $\left(\mathrm{Fe}_{\mathrm{x}} \mathrm{Mg}_{1-\mathrm{x}}\right)_{2} \mathrm{SiO}_{4}$ olivines, Earth Planet. Sc. Lett. 284 (2009) 516-526.

[41] J. Garcia-Otero, A. Garcia-Bastida, J. Rivas, Influence of temperature on the coercive field of non-interacting fine magnetic particles, J. Magn. Magn. Mater. 189 (1998) 377-383.

[42] H. Shenker, Magnetic Anisotropy of Cobalt Ferrite $\left(\mathrm{Co}_{1.01} \mathrm{Fe}_{2.00} \mathrm{O}_{3.62}\right)$ and Nickel Cobalt Ferrite $\left(\mathrm{Ni}_{0.72} \mathrm{Fe}_{0.20} \mathrm{Co}_{0.08} \mathrm{Fe}_{2} \mathrm{O}_{4}\right)$, Phys. Rev. 107 (1957) 1246-1249.

[43] E. Tronc, J.P. Jolivet, J. Livage, Mössbauer investigation of the $\gamma-\rightarrow \alpha-\mathrm{Fe}_{2} \mathrm{O}_{3}$ transformation in small particles, Hyperfine Interactions 54 (1990) 737-740.

[44] E. Tronc, A. Ezzir, R. Cherkaoui, C. Chanéac, M. Noguès, H. Kachkachi, D. Fiorani, A.M. Testa, J.M. Grenèche, J.P. Jolivet, Surface-related properties of $\gamma-\mathrm{Fe}_{2} \mathrm{O}_{3}$ nanoparticles, J. Magn. Magn. Mater. 221 (2000) 63-79.

[45] C. Cannas, A. Musinu, G. Piccaluga, D. Fiorani, D. Peddis, H.K. Rasmussen, S. Mørup, Magnetic properties of cobalt ferrite-silica nanocomposites prepared by a sol-gel autocombustion technique, J. Chem. Phys. 125 (2006) 164714.

[46] Mössbauer spectra were fitted using two sextets for A and B contributions, and three different linewidths $\Gamma$ for each pair of lines. After synthesis: $\Gamma_{\mathrm{A}}=0.231 / 0.250 / 0.275 \mathrm{~mm} . \mathrm{s}^{-1}$; $\Gamma_{\mathrm{B}}=0.272 / 0.320 / 0.364 \mathrm{~mm} \cdot \mathrm{s}^{-1}$. After annealing at $800^{\circ} \mathrm{C}: \Gamma_{\mathrm{A}}=0.232 / 0.230 / 0.234 \mathrm{~mm} \cdot \mathrm{s}^{-1}$; $\Gamma_{\mathrm{B}}=0.286 / 0.340 / 0.390 \mathrm{~mm} \cdot \mathrm{s}^{-1}$.

[47] G. Sawatzky, F. van der Woude, A. Morrish, Cation Distributions in Octahedral and Tetrahedral Sites of the Ferrimagnetic Spinel $\mathrm{CoFe}_{2} \mathrm{O}_{4}$, J. Appl. Phys. 39 (1968) 1204-1206.

[48] Z. Beji, L. S. Smiri, N. Yaacoub, J.M. Grenèche, N. Menguy, S. Ammar, F. Fiévet, Annealing effect on the magnetic properties of polyol-made Ni- Zn ferrite nanoparticles, Chem. Mater. 22 (2010) 1350-1366. 
[49] W.S. Chiu, S. Radiman, R. Abd-Shukor, M.H. Abdullah, P.S. Khiew, Tunable coercivity of $\mathrm{CoFe}_{2} \mathrm{O}_{4}$ nanoparticles via thermal annealing treatment, J. Alloy. Compds. 459 (2010) 291297.

[50] F. Fabris, Y.T. Xing, D.F. Franceschini, D.R. Sanchez, M. Alzamora, W.C. Nunes, Effects of postdeposition heat treatment on the structural and magnetic properties of $\mathrm{CoFe}_{2} \mathrm{O}_{4}$ nanoparticles produced by pulsed laser deposition, J. Appl. Phys. 122 (2017) 063901.

[51] C. Vichery, I. Maurin, O. Proux, I. Kieffer, J.L. Hazemann, R. Cortès, J.P. Boilot, T. Gacoin, Introduction of cobalt ions in $\gamma-\mathrm{Fe}_{2} \mathrm{O}_{3}$ nanoparticles by direct coprecipitation or postsynthesis adsorption: dopant localization and magnetic anisotropy, J. Phys. Chem. C 117 (2013) 19672-19683.

[52] F.K. Lotgering, On the ferrimagnetism of some sulphides and oxides, Phil. Res. Rep 11 (1956) 337-350.

[53] W. Baaziz, B. P. Pichon, Y. Liu, J.M. Grenèche, C. Ulhaq-Bouillet, E. Terrier, N. Bergeard, V. Halté, C. Boeglin, F. Choueikani, M. Toumi, T. Mhiri, S. Begin-Colin, Tuning of synthesis conditions by thermal decomposition toward core-shell $\mathrm{Co}_{\mathrm{x}} \mathrm{Fe}_{1-\mathrm{x}} \mathrm{O} @ \mathrm{Co}_{\mathrm{y}} \mathrm{Fe}_{3-\mathrm{y}} \mathrm{O}_{4}$ and $\mathrm{CoFe}_{2} \mathrm{O}_{4}$ nanoparticles with spherical and cubic shapes, Chem. Mater. 26 (2014) 5063-5073. 